\title{
Construction of Multimedia Teaching Platform for Ecological Economics Course Based on Information Technology
}

\author{
https://doi.org/10.3991/ijet.v12.i09.7486 \\ Fanglin Wang \\ Chizhou Vocational and Technical College, Chizhou, China \\ hnah321@163.com
}

\begin{abstract}
To solve the problems of dull multimedia teaching mode, untargeted education, and low efficiency of the course of ecological economics, we have applied information technology in multimedia education, and designed a new multimedia education platform. The aforesaid multimedia education platform consists of three modules, i.e. login module, expert module and student module. We tested the effect of the newly-built multimedia education platform based on information technology via teaching experiment, and results demonstrate that this multimedia education platform is helpful for implementing targeted teaching and guidance according to students' characteristics, to raise students' learning initiative and ensure teaching efficiency. These findings indicate the new education platform is helpful for providing more vivid teaching contents, stimulating students' learning initiative, and improving teaching quality.
\end{abstract}

Keywords-Information technology, ecological economics, multimedia, teaching platform

\section{Introduction}

In recent years, to accelerate the reform of educational modernization, the state has proposed educational informatization. Educational informatization requires educational institutions to reform and innovate education with the mature information technology, to improve education quality [1]. Ecological economics is an integrative curriculum developed during the period from the 1950 s to the 1960 s, which covers bionomics, economics, etc., and is mainly for exploring theories on and methods of realization of harmonious development between man and nature [2]. This is a demanding curriculum in respect of both theory and practice, and has been being a tough course in teaching. Under the background of educational informatization, colleges and universities, for the purpose of improving the teaching efficiency of ecological economics, start to explore and employ multimedia teaching model that is being widely applied, to realize course learning of students via multimedia education platform. Comparing with traditional teaching model, this model is much more advanced, which, via the utilization of information technology, can realize educational resource sharing, 
and improves teaching efficiency. It is widely accepted by the colleges and universities in China. In the process of using, however, the existing multimedia education platform also has some defects. (1) Teaching fails to be innovated accordingly. Presently, most colleges and universities just combine traditional teaching model with multimedia education platform, and fail to implement targeted teaching according to students' abilities of comprehension, digestion and absorption. Thus, some students with poor comprehensive ability cannot keep pace with the progress of the curriculum. (2) Most students appear to be less initiative in learning, especially in the course of ecological economics. This is because the course of ecological economics relates to many theories of economics, which are dull to students. (3) The functions of the existing multimedia education platforms are not perfect. Particularly, such platforms are failed to be provided with module for self-directed learning for students to help students digest knowledge acquired at classroom. It is of no use to solely add functions to such multimedia platforms with the existing computer technology [3].

Information technology, also referred to artificial technology, is a new computer technology developed in recent years. It is mainly used in studying how to simulate human behaviors of thinking and learning with computer. The intelligence systems developed with information technology have certain learning, reasoning and judging ability, which is realized by designing programs and formulas about the process of thinking, learning and reasoning of human brain on the computer. Applying information technology in multiple education design is helpful to simulate teachers with computational intelligence to process knowledge in a rapid, accurate, automatic and scientific way. According to this principle, information technology can be utilized for designing a multimedia education platform which can enable targeted teaching of ecological economics and overcome the defects of the current technologies.

\section{State of the art}

Presently, Europe, America and Japan are the leaders in information technology, mainly covering machine learning, neural network and fuzzy processing [4]. Maroni and Flores introduced the development and evaluated a pedagogical agent that used artificial intelligent techniques (such as Influence Diagrams and Bayesian Networks) to select and issue pedagogical strategies for students to have an experience of simulating complex clinical cases in a simulator called SimDeCS (Simulation for Decision Making in the Health Care Services). This simulator is intended to help the educator involved in this activity of matching theoretical learning and essential clinical practice. The test results show that good teaching efficiency is achieved [5]. Information technology is adopted in the fifth generation of electronic computer developed in Japan latest, which has the following functions, including intelligent interface, autonomous learning ability, learning and reasoning ability, and automatic image and voice recognition capability. It is a large progress practically [6]. Aparicio and Buenaga applied educational informatization technology in medical teaching. This system can automatically detect significant concepts that are available within a given clinical case and facilitate an objective examination, which follows a proper selection process of 
the case in which the students' knowledge level is taken into consideration [7]. Feng and Xiao built a building information model, putting all building stages into the scope of information management, discussing the application of parameterized model technology in architecture teaching, and affirming the effectiveness of the application [8]. The University of Science and Technology Beijing, through three-year systematic study, developed computer-based intelligence adjudication technology, applying information technology in physical experiment teaching process. Contrast experiments show that this technology is helpful to improve students' ability of experimental report writing, and promote the development of students' ability of experimental data processing and experimental analysis [9]. It is thus clear that the 21 st century is an information era, when multimedia teaching mode is widely adopted in most colleges and universities with the further advancement of network application. But the simple packing of hardware cannot address the needs of ordinary classroom multimedia teaching, and it is urgent to solve the problem of perfectly combining network with digital resources for the construction and management of campus information. The rapid development of educational informatization technology is of great significance to promoting the equity and development of education. So far, educational informatization technology has been transformed from the "application" stage in to the stage of "innovation" and "integration" in China [10]. With the advent of the Internet era, the development of educational informatization will reach a new level, and small and diversified terminal equipment will be developed. But the terminal equipment also has some defects. Firstly, user cannot have an access to a complete web page via mobile devices such as mobile phone, and such mobile devices are usually poorly compatible with the applications, which will greatly reduce the desired effect and users' interest [11]; secondly, this research mainly targets teachers and students of the specialty of economics. In the teaching process of economics, with the increase of students and problems and the expansion of classroom, teachers' teaching pressure becomes increasingly high. For example, it is hard for students seated themselves far away from the teacher to hear the teacher clearly. If the teacher employs a public address set such as headset, it is noisy to students seated themselves near the teacher. Besides, it becomes complicated for teachers to design questions and for students to check exam results. In view of this, the practice of building a multimedia teaching platform of ecological economics which can overcome the defects set out above can provide reference and enlightenment for information-based economics teaching in future.

\section{$3 \quad$ Model analysis}

\subsection{Theory of dimension division}

In accordance with the current situation and needs of educational informatization, the basic information content system of educational informatization can be described from three dimensions, namely education type, core elements and research elements, as shown in Fig. 1. 


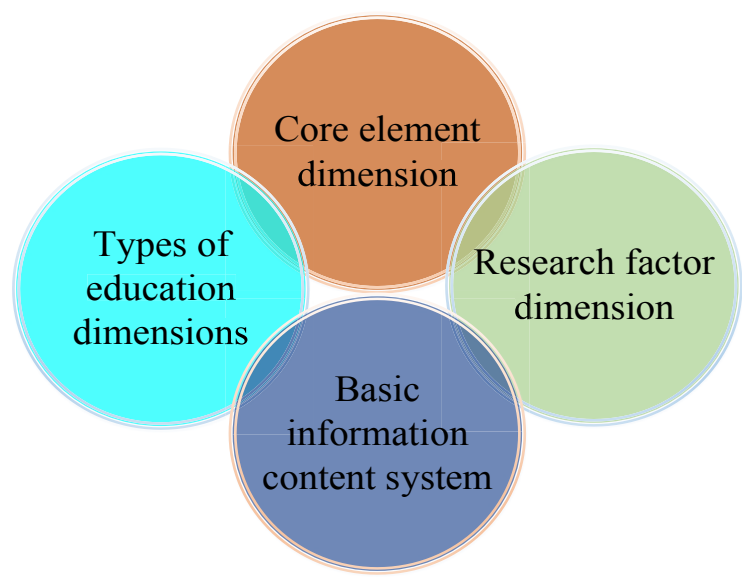

Fig. 1. Dimension division of educational informatization system architecture

According to Fig. 1, the dimension of education type means that the educational informatization system is divided into basic education informatization, vocational education informatization, higher education informatization, continuing education informatization and educational management informatization from the aspect of educational development. The dimension of core elements means that the core elements of educational informatization are, according to the research results of the development and evaluation of educational informatization at home and abroad, summarized to include: basic facilities, resources, applications, management informatization and guarantee system. The dimension of research elements, from the perspective of current development situation of educational informatization, include educational informatization standard system, educational informatization plan, educational informatization policy, educational informatization depository, trainings on educational informatization, hot spots of educational informatization, and outstanding cases of educational informatization, covering basic facilities, resource construction, talent cultivation, application system, industrial development, information standard, policy mechanism, excellent case, and Chinese and foreign informatization.

\subsection{Design scheme}

To solve the problems of the existing multimedia teaching platforms, newlydesigned teaching platform should, in combination with information technology, have the following functions. Firstly, it should be able to judge student behaviors by means of certain intelligence algorithm according to the available data of students, to get knowledge of students' learning ability and throw out a suggestion to students accordingly. Secondly, it should be able to determine students' weakness in learning via statistics of students' exam results, and inform the teacher and students of the weakness. Thirdly, it should be able to adjust the teaching contents from time to time according to students' learning condition, and evaluate the teaching result of each class, to provide a basis for teaching supervisor to offer suggestions to teachers. 
Besides analysis of functional requirements, an overall system structure design can be made. It is suggested to adopt the $\mathrm{B} / \mathrm{S}$ architectural mode which is economical for teaching platform construction, and helpful for students and teachers to log in the system remotely for learning and teaching, the C\# language that is adopted most widely and enjoys mature technology as the development language, and the Oracle technology that facilitates data storage and inquiry for database development. The whole system architecture can be designed to consist of five parts: specialized knowledge base, expert module, student model, teaching and control module, and user interface module, as shown in Fig. 2.

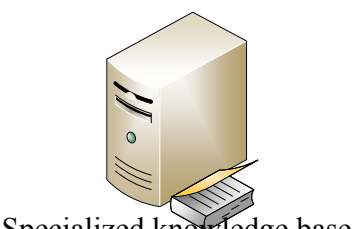

Specialized knowledge base

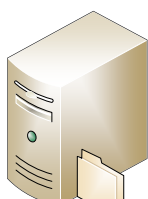

Expert module

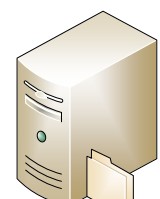

Student module

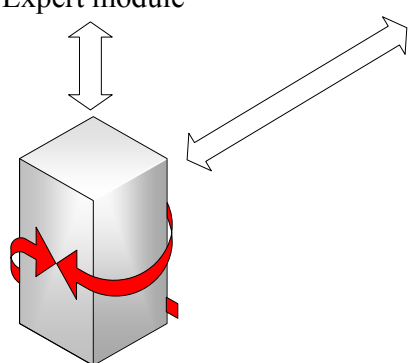

Teaching and control module

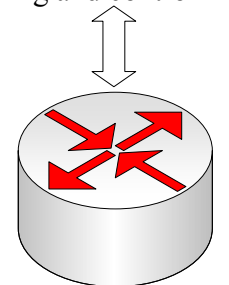

User interface module

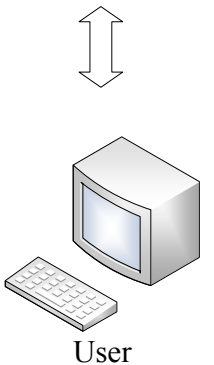

Fig. 2. Overall system structure diagram 
The specialized knowledge base is mainly for storing teaching courseware, videos, and test papers, which can automatically generate practical teaching contents via the intelligence system for teaching, and produce test papers as required according to students' learning condition, to enhance teaching pertinence.

The teaching and control module is mainly for controlling the functions of the system. By executing certain command or via certain interface operation, the functions can be selected as desired. The expert module and student module are mainly designed to enhance teaching pertinence and students' independent learning ability and learning interest. The student module is mainly for helping improve students' independent learning ability, which is of a structure of neural network. Generally speaking, every student has his/her own learning characteristics due to different learning styles and levels of comprehensive ability, and the traditional teaching mode is inadequate to help enhance students' independent learning ability. In view of this, it is necessary to design the system to have this function, so as to enable students to select learning content and obtain pertinent guidance in the whole learning process. Only in this way, the learning effect can be guaranteed. In the neural network structure adopted for this system [9], knowledge can be expressed in the form of weight coefficient set and threshold value set, as below:

$$
\begin{gathered}
\operatorname{IF}\left(x_{1}, \ldots . . x_{n}\right)^{T}=(1,0, \ldots . .1)^{T} \\
\operatorname{THEN}\left(y_{1}, \ldots . . y_{n}\right)^{T}=(0,1, \ldots . ., 0)^{T}
\end{gathered}
$$

$\left(x_{1}, \ldots x_{n}\right)^{T}$ stands for knowledge point, and $\left(y_{1}, \ldots y_{n}\right)^{T}$ stands for judgment model of knowledge point. With this judgment model, all knowledge points can be put into a neural network for judgment to obtain an intelligent outcome.

\section{$4 \quad$ Teaching platform implementation}

\subsection{Login module implementation}

Since the B/S architectural mode (namely server-client mode) is adopted for this teaching platform, the login interface is presented in the form of webpage. The three types of this system accessible to this system must enter correct user ID and password to $\log$ in. The concrete implementation process is: the system administrator grants user ID and password to users and stores the relevant data in the database; the user ID and password entered by users will be compared with the data in the database, and users will be allowed to $\log$ in if the data turns out to be correct, or rejected to log in if the data turns out to be wrong with relevant prompt. The login interface is as shown in Fig. 3. 


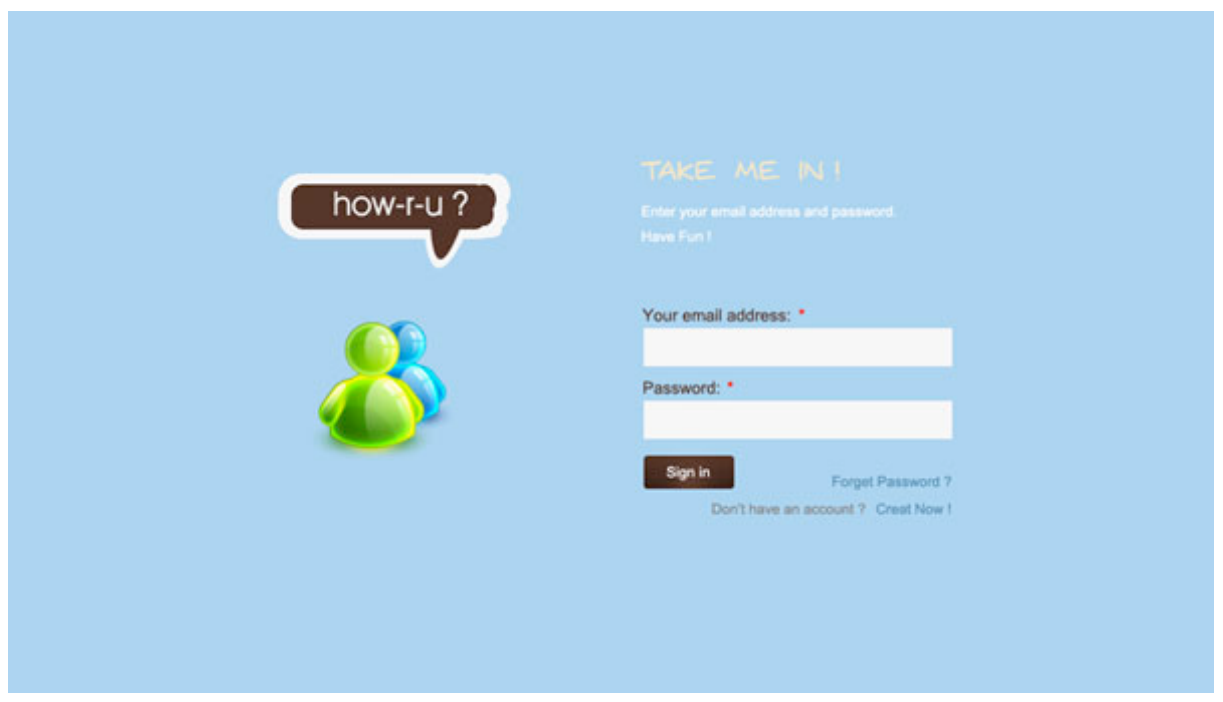

Fig. 3. Login interface of teaching platform

\subsection{Expert module implementation}

The functions of the expert module are mainly realized via a teaching inference engine interpreter. The inference engine is mainly used for judging students' condition, and generating online test papers and teaching contents based on students' condition, while the interpreter is mainly for responding to the process of students' answering questions and doing test papers, and explaining difficult knowledge points for students.

The algorithm parameters of the interference engine include student number, password, student type, sex, and EMAIL. The flow diagram of the algorithm is as shown in Fig. 4.

For the algorithm of inference engine, forward reasoning is adopted. Forward reasoning means regarding a rule as available rule if the fact is determined to match with the left of the rule with the algorithm of forward reasoning according to the current situation, and selecting one of the available rules and putting the right of the rule to match with the fact. This process is circulatory until the problem is solved or there is no available rule. In teaching practice, it requires to do three reasoning processes. The first process is to make judgment according to the online test outcomes of students, the second process is to take the test outcomes obtained in the first process as input data of neural network to obtain the final outcomes (which will be taken as knowledge points), and the third process is to design exercises and select teaching contents according to the knowledge points. Among the three processes, the second one is of highest importance, which is a process of self-directed learning and judging process of neural network. 


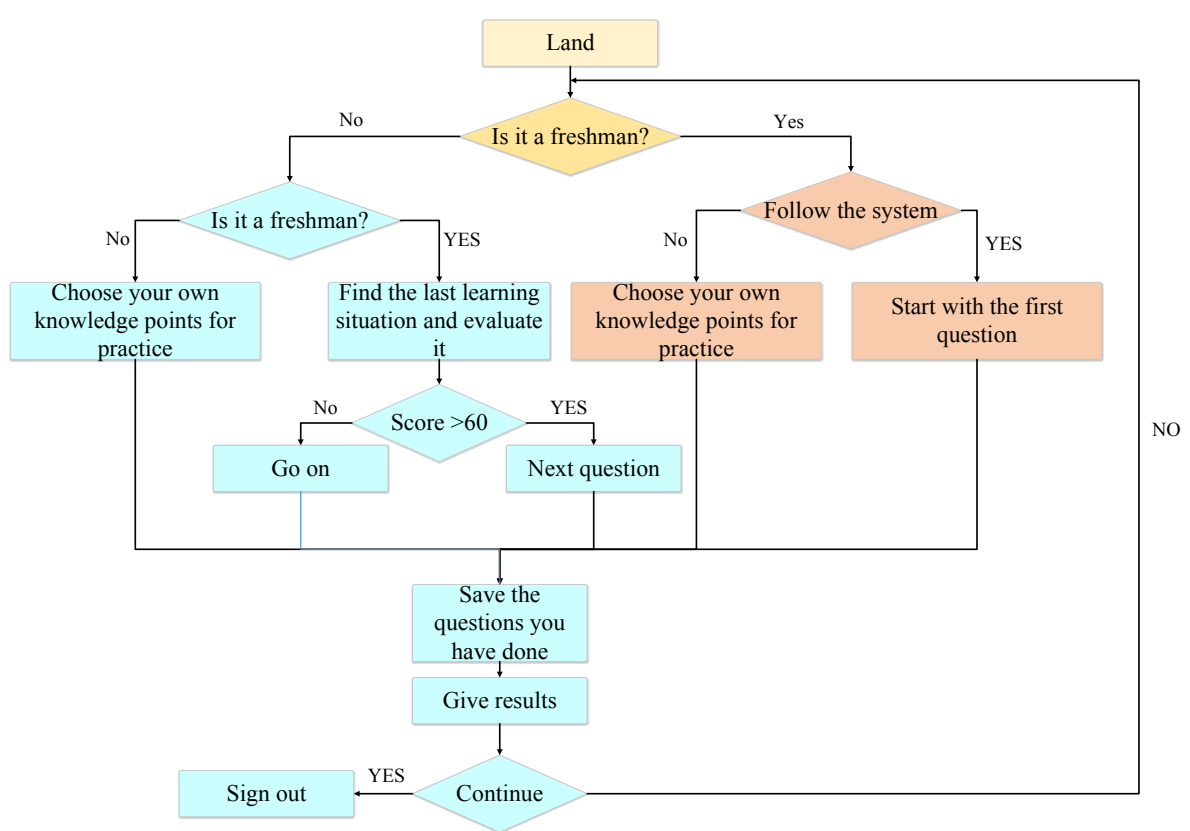

Fig. 4. Flow diagram of inference engine algorithm

\subsection{Student module implementation}

The student module mainly consists of three parts, namely self-diagnosis, online learning, and historical exercise. Concerning the three parts, the BP neural network structure is adopted for diagnosing students' conditions according to the situations of online learning and historical exercise. Based on the diagnosis results, the system can update and improve the contents of online learning, to enhance the pertinence of students' self-directed learning. The key to the implementation of the whole student module rests in the implementation of the BP neural network. In the teaching process of ecological economics, 200 representative questions selected by experts for college students were sampled for examination of the course of ecological economics, and 3000 sets of samples were obtained. The 3000 sets of samples were divided into two groups equally, one group as training samples, and the other as test samples. With the 200 questions as input parameters of the neural network, all connection weights of the neural network and the threshold value of each neural network can be determined ultimately, this can be expressed in the form of vector and used for realizing students' self-directed learning. The process for utilizing the teaching platform for teacherstudent interaction is as shown in Fig. 5. 
Paper-Construction of Multimedia Teaching Platform for Ecological Economics Course Based on...

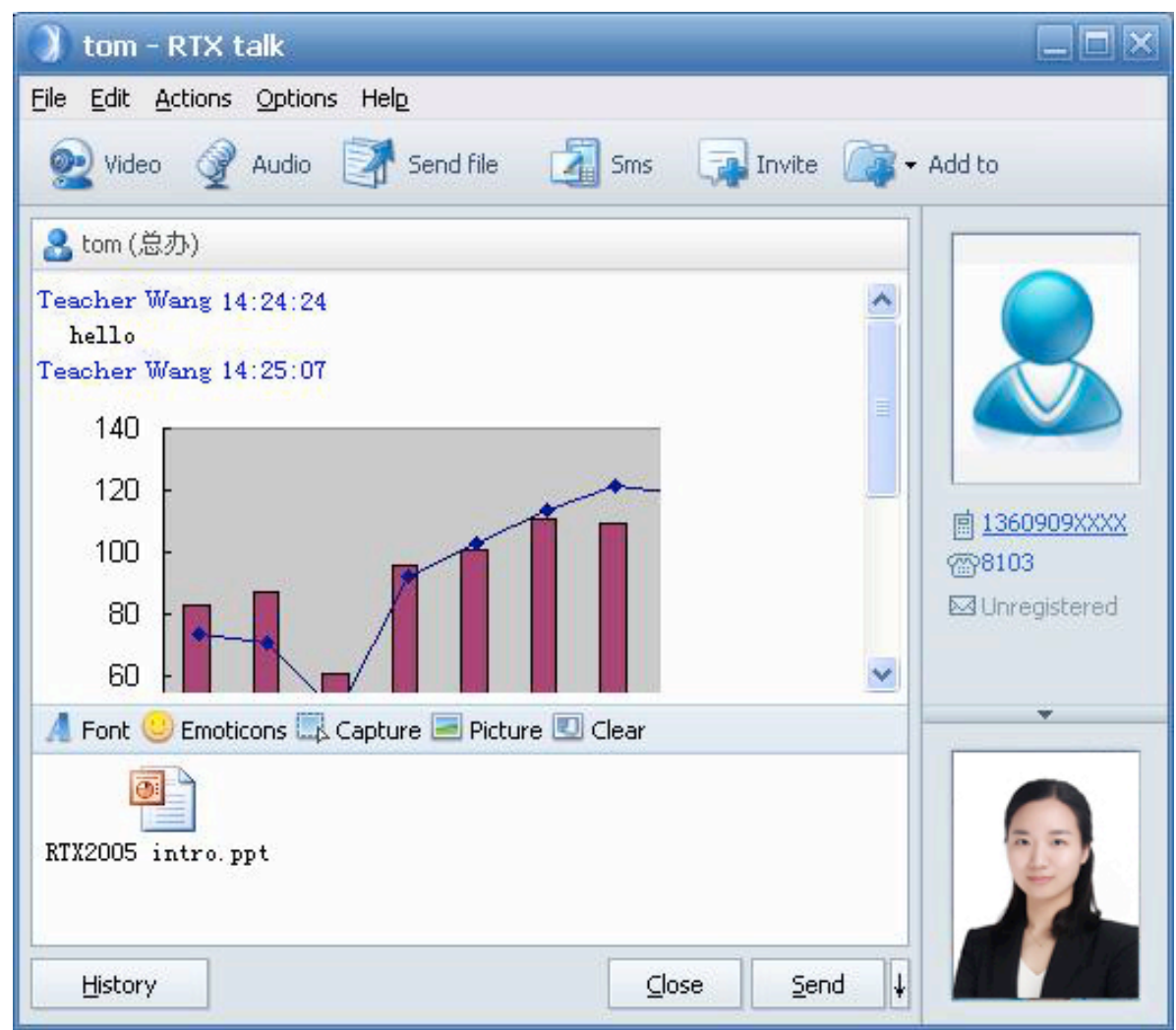

Fig. 5. Teacher-student interaction via the teaching platform

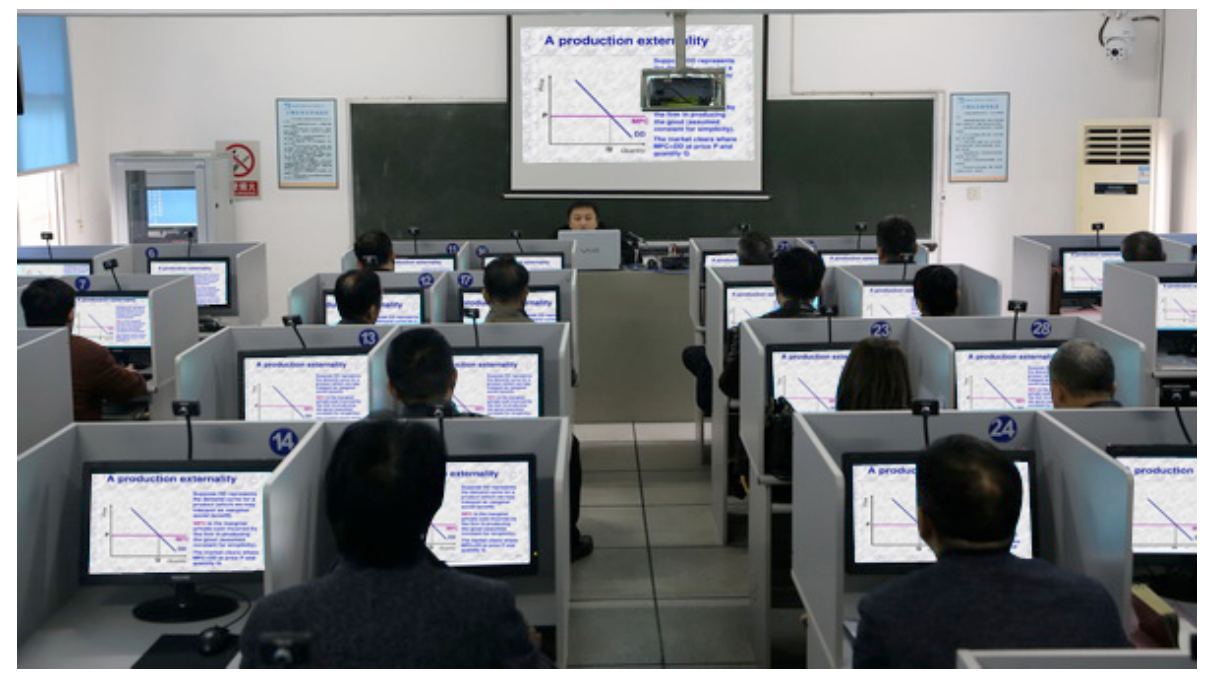

Fig. 6. Application of information technology in multimedia platform of the course of ecological economics 


\subsection{Effect check}

To check the effect of the new teaching platform, 150 students and 4 teachers of one class of ecological economics were sampled for test. The 150 students and 4 teachers were divided into two groups equally. One group was taken as the control group, for whom traditional multimedia teaching platform was adopted, and the other group as the experimental group, for whom the new teaching platform was adopted. Statistics shows that the 150 students studied knowledge online 1564 times, and took 5678 exams online in total; the 4 teachers logged in the teaching platform 186 times, had 1653 activities online, and assigned homework 32 times in total. In one semester, 4 formal exams were organized in total. The average scores of the two groups were taken, questionnaire survey on course learning satisfaction was carried out over the two groups after each exam, and the ratio of the number of students satisfied with classroom learning to the total number of students was calculated. The results of the teaching experiment are as shown in Tab. 1.

Table 1. The results of the teaching experiment

\begin{tabular}{|c|l|c|c|c|c|}
\hline Class & \multicolumn{1}{|c|}{ Exam type } & $\begin{array}{c}\text { Average } \\
\text { score }\end{array}$ & $\begin{array}{c}\text { Number of } \\
\text { excellence }\end{array}$ & $\begin{array}{c}\text { Number of } \\
\text { failure }\end{array}$ & $\begin{array}{c}\text { Satisfaction } \\
\text { degree }\end{array}$ \\
\hline \multirow{4}{*}{$\begin{array}{c}\text { Experimental } \\
\text { group }\end{array}$} & $1^{\text {st }}$ exam & 82.4 & 32 & 11 & $87.7 \%$ \\
\cline { 2 - 6 } & Mid-term exam & 87.1 & 34 & 8 & $89.5 \%$ \\
\cline { 2 - 6 } & $2^{\text {nd }}$ exam & 83.3 & 38 & 12 & $91.3 \%$ \\
\cline { 2 - 6 } & Final exam & 85.2 & 40 & 7 & $93.7 \%$ \\
\hline \multirow{4}{*}{ Control group } & $1^{\text {st } \text { exam }}$ & 78.3 & 20 & 15 & $67.8 \%$ \\
\cline { 2 - 6 } & Mid-term exam & 81.2 & 22 & 13 & $73.5 \%$ \\
\cline { 2 - 6 } & $2^{\text {nd }}$ exam & 76.3 & 25 & 12 & $72.7 \%$ \\
\cline { 2 - 6 } & Final exam & 74.4 & 19 & 14 & $69.6 \%$ \\
\hline
\end{tabular}

According to the table, concerning course score, the experimental group are superior to the control group in respect of average score, the number of excellence, and the number of good, and the experimental group have largely got improved in final exam, indicating that the effect of the new teaching platform is better; concerning satisfaction, students' interest rises as they continue to use the new teaching platform, indicating that the new teaching platform makes a great difference in arousing students' learning interest. It is thus clear that the teaching platform designed in this paper is worth being promoted. An analysis of its advantages shows that that the teaching platform is provided with a basic information base system is helpful for students and teachers to acquire relevant information rapidly and conveniently, and to improve learning and teaching efficiency. For example, user can have an access to the base system via mobile phone at any time in any place to obtain the desired resources and information, without having to be provided with a computer with Internet connection. Although users could have an access to the web-end of the system platform via mobile phone in the past, they were bothered by the resolution inconsistency between the web-end and the mobile client or the inconvenience of searching. Relatively, this teaching platform can greatly raise the efficiency of information acquisition, and then 
raise students' satisfaction; besides, this study can largely help students and teachers in knowledge exploration on equal terms. For example, teachers can encourage students to do more thinking, raise questions, form divergent thinking, and tackle problems flexibly via effective guidance and hint, to help students relieve from learning stress, raise learning interest, and improve learning efficiency.

\section{Conclusions}

The latest information technology is applied in the teaching platform which is designed with information technology, and the teaching platform is designed to be with the functions of helping students' self-directed learning and teaching inference engine, which has considerably alleviated the problems of the traditional teaching platform, such as low education pertinence, students' low initiative, and imperfect functions. Teaching experiment proves that the new teaching platform is feasible, which is helpful to raise students' learning interest, and update the teaching contents according to students' learning progress, to raise the teaching efficiency and accelerate the construction of educational informatization. Thus, we will focus more on curriculum design pertinent to this platform in following researches.

\section{References}

[1] Dai, W., Fan, L. Discussion about the Pros and Cons and Recommendations for Multimedia Teaching in Local Vocational Schools, Computer Knowledge \& Technology, 2011, vol. 33(1), pp. 1144-1148.

[2] Ott, C., Schmid, A., Titze, S., et al. Information and Comunication Technology in Education as an Environment of the Intelligent Tutoring Systems. Interni Izvještaj, 2003, vol. 5(4), pp. 186.

[3] Maroni, V., Flores, C.D., Cazella, S.C., et al. Development and Evaluation of an Intelligent Pedagogical Agent for the SimDeCS Software. Procedia Technology, 2013, vol. 9, pp. 1217-1226. https://doi.org/10.1016/j.protcy.2013.12.136

[4] Matthews, B. Towards an Understanding of the Social Issues in Information Technology: concerning computers, intelligence and education. Journal of Information Technology for Teacher Education, 2006, vol. 1(2), pp. 201-213. https://doi.org/10.1080/096202992001 $\underline{0205}$

[5] Aparicio, F., Buenaga, M.D., Rubio, M. An intelligent information access system assisting a case based learning methodology evaluated in higher education with medical students. Computers \& Education, 2012, vol. 58(4), pp. 1282-1295. https://doi.org/10.1016/j.comp edu.2011.12.021

[6] Feng, Y.N., Xiao, N. Building information model based on parametric Intelligent Technology. Shanxi Agricultural Economy, 2016, vol. 6, pp. 124-124.

[7] Wu, P., Zhang, S.P., Li, L., et al. The deeper integration of information technology and physics experiment course. Physics and Engineering, 2016, vol. 26(5), pp. 22-26.

[8] Liu, W.S., Liu, C., Pan, J., et al. Construction of educational information technology support service system in Heilongjiang Province. Journal of Heilongjiang College of Education, 2015, vol. 15(6), pp. 29-30. 
Paper-Construction of Multimedia Teaching Platform for Ecological Economics Course Based on...

[9] Xu, F.Y. Applying modern educational technology to promote the process of educational informatization. China Educational Technology \& Equipment, 2010, vol. 24(14), pp. 142143.

[10] Zhang, J., Qu, D., Li, Z. Recurrent neural network language model based on word vector features. Pattern Recognition \& Artificial Intelligence, 2015, vol. 28(4), pp. 299-305.

\section{Author}

Fanglin Wang is an associate professor in the Chizhou Vocational and Technical College, Chizhou 247100, China (hnah321@163.com).

Article submitted 25 April 2017. Published as resubmitted by the authors 24 July 2017. 